\title{
Endogenous switching costs and exclusive systems: A reply
}

\author{
BEGOÑA GARCIA MARIÑOSO*
}

City University of London

\begin{abstract}
In a critique of my paper "Technological Incompatibility, Endogenous Switching Costs and Lockin”, Haucap (2003) argues that its applicability for policy purposes is limited by its reliance on the assumptions of no market growth and of the firms' ability to commit to technological compatibility. In this note, I show that the results in the paper still hold with market growth and I argue that technological compatibility is a time consistent strategy.
\end{abstract}

\section{Introduction}

In markets for systems consumers purchase the systems' parts sequentially, acquiring first a platform and later buying its complements. With sequential purchases and technological incompatibility consumers must replace platforms if they switch brands. These replacement costs are endogenous switching costs, the prices of the equipment to replace. "Technological Incompatibility, Endogenous Switching Costs and Lock-in"1 argues why firms might not use inter-brand incompatibility as a strategy to create switching costs in order to monopolize complement markets.

The paper shows that incompatibility generates rents from locked-in consumers in the complement market. However, with "replacement costs" and competition in the platform market, firms completely compete away these ex post rents when platforms are sold. In fact, if one was to be concerned, it would be about excess compatibility! Haucap criticises the paper pointing at two of its assumptions: in it there is no market growth and firms can commit to compatibility. In this response, I show that market growth can reinforce the main result in the JIE paper (compatibility is more profitable than incompatibility), and I argue that compatibility is a credible strategy. ${ }^{2}$

\footnotetext{
* Mailing address: Department of Economics, City University of London, Northampton Square, London ECIV 0HB. E-mail: B.Garcia-Marinoso@ city.ac.uk

${ }^{1}$ Garcia-Mariñoso (2001), henceforth the JIE paper.

${ }^{2}$ All supporting calculations can be obtained from the author
} 


\section{What happens with the JIE results if there is market growth (new consumers)?}

With no new consumers (JIE paper) firms can perfectly price discriminate between switching consumers who buy a bundle (platform and complement) and old consumers who buy a complement. This has two effects. When complements are purchased (second period) firms reduce the price of the bundle to attract switching consumers (who are locked into the rival's platform) and raise the complement price paid by locked-in consumers. In consequence, switching is subsidised ${ }^{3}$ and is excessive. Perfect price discrimination also implies that second period equilibrium prices are independent on initial platform market shares. Hence, expectations on future prices play no role in consumers' initial platform choice and do not affect the elasticity of platform demand. As a result, firms compete away all second period rents when they initially sell platforms and compatibility is overall more profitable than incompatibility.

Haucap rightly points out that with new consumers firm cannot price discriminate between all consumer groups: brand new, switching and old. Yet, firms can price discriminate between old customers (complement buyers) and switching and new consumers (bundle buyers). ${ }^{4}$ The question is how this imperfect price discrimination affects the subsidising of switching costs and the elasticity of platform demand in the first period. To answer, one must study the second period profit (1) and price reaction functions for firm A (equations (2) and (3)) $)^{5}$ :

(1) $\pi_{A}=\frac{s_{A}}{L} \cdot\left(P_{A Y}-c_{y}\right) \cdot I_{A}+\left(P_{A}-c\right) \cdot\left(\frac{s_{B}}{L} \cdot I_{B}+\frac{s_{N}}{L} \cdot I_{N}\right)$

(2) $P_{A Y}=\frac{\left(c_{y}+P_{B}+L\right)}{2}$

(3) $P_{A}=\frac{1}{2}\left(c+L+\frac{s_{B}}{\left(L-s_{A}\right)} P_{B Y}+\frac{s_{N}}{\left(L-s_{A}\right)} P_{B}\right)$

Firm A bundle price $P_{A}$ is paid by switching and new consumers. To attract switching consumers, whose alternative is to buy B's complement, firm A ought to discount its bundle. However, in doing this, firm A reduces the margin earned on "non locked-in" new consumers. This mitigates A's incentives to discount the bundle. Equation (3) shows that if the share of new consumers increases, $P_{A}$ is more responsive to the price of B's bundle $\left(P_{B}\right)$. As a result, $P_{A}$ grows (since $\left.P_{B}>P_{B Y}\right)$. Due to price complementarities, all prices increase, but crucially bundle prices raise more than complement prices. Thus, with market growth the subsidising of switching costs is reduced, (although not entirely eliminated).

Imperfect price discrimination implies that first period market shares impact on second period equilibrium prices. For example, the second period equilibrium bundle price for firm A is:

\footnotetext{
${ }^{3}$ The switching cost is defined as the difference between the bundle price and the complement price.

${ }^{4}$ With trade-ins, firms could perfectly price discriminate and the JIE results would exactly follow.

${ }^{5}$ This notation follows Haucap's paper. $s_{N}$ is the share of new consumers and $I_{N}=\left(P_{B}-P_{A}+L\right) / 2$ is the indifferent consumer in the new consumer market.
} 
(4) $P_{A}^{*}=c_{y}+L+\frac{2}{3} \cdot \frac{3 \cdot L \cdot s_{B}-3 \cdot s_{B}^{2}-4 \cdot s_{N} \cdot s_{B}+5 \cdot L \cdot s_{N}+s_{N}^{2}}{3 \cdot L \cdot s_{B}-3 \cdot s_{B}^{2}-3 \cdot s_{N} \cdot s_{B}+4 \cdot L \cdot s_{N}} \cdot c_{x}$

The recognition of this price interdependence alters firm A's incentives to undercut B's platform price in the first period and affects the consumers' initial platform choice. These facts determine the extent to which second period lock-in rents are competed away at $\mathrm{t}=1$.

By undercutting firm B's platform price at $\mathrm{t}=1$, firm A's market share $\left(s_{A}\right)$ grows to the expense of firm B's $\left(s_{B}\right)$. If so, firm A has a smaller market of switching consumers and lesser incentives to discount its bundle at $\mathrm{t}=2$ (see equation 3 ). Reversibly, firm $\mathrm{B}$ has more incentives to discount its bundle. Indeed, $\partial P_{A}^{*} / \partial s_{A}>0$ and $\partial P_{B}^{*} / \partial s_{A}<0$. By equation 2 : $\partial P_{A y}^{*} / \partial s_{A}<0$ and $\partial P_{B y}^{*} / \partial s_{A}>0$.

The statement that $\partial P_{A y}^{*} / \partial s_{A}<0$ is crucial. It opposes the main result in the exogenous switching cost literature: with a large market share, a firm increases its second period price to exploit its locked-in customers. In that literature if consumers anticipate the future increase in price, they are less attracted by first period price cuts. This demand inelasticity can imply that first period competition does not exhaust ex post lock-in rents (Klemperer, 1992).

On the contrary, with replacement costs and new consumers, first period demand becomes more elastic if consumers are rational. ${ }^{6}$ Rational consumers are eager to accept A's price cut as they recognise the subsequent reduction in the second period complement price. In consequence, competition is exacerbated at $t=1$ (there is more ex ante competition than without market growth), and all ex post rents from lock-in can be eroded by the excessive ex ante competition. With rational consumers and market growth firms are better off with compatibility. ${ }^{7}$

\section{Credibility of the compatibility choice}

In the JIE paper, compatibility is the best option ex ante, but at $\mathrm{t}=2$ firms would profit from a bilateral turn into incompatible technologies. Haucap raises the question of the credibility of the compatibility choice: If compatibility is chosen ex ante would firms revert to the incompatible regime at $\mathrm{t}=2$ and this be expected by consumers? I argue that for most circumstances firms would not revert to the incompatible regime. Compatibility is a credible strategy.

There are several ways in which compatibility can be initially attained. Compatibility can be a result of a contract. If this contract is made public to consumers, a bilateral or individual deviation from its terms could bring the firms to court. If enforcement is possible and penalties are likely, compatibility is credible. Compatibility can also result from an informal agreement between firms on design. These agreements typically entail some exchange of technical information and the running of some tests to check that

\footnotetext{
${ }^{6}$ With no new consumers, demand elasticity is the same whether consumers are rational or not.

${ }^{7}$ If $s_{N}$ is sufficiently large.
} 
products work well together. If design decisions are non-reversible, compatibility is credible. Moreover, if design decisions are reversible, compatibility is credible too.

For example, consider Firm $\mathrm{A}^{\prime} \mathrm{s}^{8}$ decision to revert designs at $\mathrm{t}=2$. At $\mathrm{t}=2$, platforms have been sold and the technical information about them has been exchanged. Therefore, the only option for firm $\mathrm{A}$ is to alter the design of its complement by making it noncompatible with B's platform. ${ }^{9}$ If she does this, she worsens her position in the switching market by imposing a switching cost to its consumers. Her position in her old customer market does not improve, as her decision does not affect these consumers' switching costs. Indeed, if $c_{x}$ is small, firm $A$ reduces its profits relative to the situation with full compatibility. ${ }^{10}$ Thus, firm A would not unilaterally deviate.

Not only this, but under the JIE assumptions, at $\mathrm{t}=2$ the game in which firms $\mathrm{A}$ and $\mathrm{B}$ choose to design compatible or incompatible complements has a prisoner dilemma structure, in which each firm's dominant strategy is to design a compatible complement. This suggests that even if firms bilaterally agreed to produce incompatible complements, they would need to establish punishments, which prevented them from individually breaking their agreement.

Perhaps the only concern with regards to the achievement of compatibility is that firms lie to consumers and to rivals in the first place, disclosing inadequate or untruthful technical information about their platforms and/or publicising compatibility to consumers when they are aware that this will not be a possibility. I believe that this is possible but unlikely as firms can be explicitly punished in court or implicitly be punished by consumers who will distrust their future claims on technology.

\section{Conclusion}

The new results reinforce the JIE paper conclusion that in markets for systems, one should not be concerned about the possibility that firms intend to tie consumers and monopolise markets by providing exclusive applications. Compatibility (non-exclusive applications) turns out to be optimal (and in most cases credible) with and without market growth.

Yet, this conclusion is not without caveats. As stressed by Haucap, one limit is the potential size asymmetries between firms. More generally, the major limit is in the consideration of asymmetries in the type of market structure and firms in the marketplace. An example is if multi-product firms compete with single product firms. It is not my intention here to provide a full typology of circumstances, but there might well be some where incompatibility might be used as an anticompetitive tool.

\section{$5 \quad$ References}

Garcia Mariñoso, B. (2001) "Technological Incompatibility, Endogenous Switching Costs and Lock-in,” Journal of Industrial Economics XLIV: 281-298.

\footnotetext{
${ }^{8}$ The same argument works for firm B.

${ }^{9}$ Firm A cannot change the design of the platform as it has already been sold to consumers and information about it has been disclosed to the rival.

${ }^{10}$ Firms B's profits increase.
} 
Haucap, J. (2003) "Endogenous Switching Costs and Exclusive Systems Applications," Review of Network Economics 2.

Klemperer, P.D. (1992) "Competition when Consumers have Switching Costs: An Overview with Applications to Industrial organization, Macroeconomics and International Trade," Review of Economic Studies 62: 515-539. 